\title{
RESEARCH PAPER \\ IMPROVING MECHANICAL PROPERTIES OF ALUMINIUM ALLOY THROUGH ADDITION OF COCONUT SHELL-ASH
}

\author{
A. Apasi*1' D. S. Yawas ${ }^{1}$, S. Abdulkareem ${ }^{2}$ and M. Y. Kolawole ${ }^{3}$ \\ ${ }^{1}$ Department of Mechanical Engineering, Ahmadu Bello University, Zaria, Nigeria \\ okomasi@yahoo.com*,dyawas@yahoo.com \\ ${ }^{2}$ Department of Mechanical Engineering, University of Ilorin, Ilorin, Nigeria \\ e-mail:sulkarm@yahoo.com \\ ${ }^{3}$ Department of Mechanical Engineering, Kwara state University, Malete, Nigeria \\ Corresponding author: maruf.kolawole@kwasu.edu.ng
}

\begin{abstract}
This paper investigates the microstructure and mechanical properties of aluminum alloy (Al-Si$\mathrm{Fe}$ ) reinforced with coconut shell-ash particulate. The aluminium (Al-Si-Fe) alloy composite was produced by a double-stir casting process at a speed of 700 rpm for 10 and 5 minutes at first and second stirring respectively. The samples produced from addition of 0-15 wt\% coconut shellash particles (CSAp) were prepared and subjected to microstructural and mechanical properties testing. The results of the microstructural analysis of the composite reveal a fairly uniform distribution of the coconut shell-ash particles in the matrix with increase in volume fraction of CSAp. The mechanical property test results revealed that, hardness of the developed composite increased with increasing percentage weight of CSAp. Also the tensile and yield strength at $0.2 \%$ offset values of Al-Si-Fe/CSAp composite increased with percentage increase in CSAp up to 9\% addition above which a little decrease in both tensile and yield strength was observed.
\end{abstract}

Keywords: Matrix, coconut shell, mechanical properties, stir-casting, particulate, reinforcements

\section{INTRODUCTION}

Particulate reinforced Metal Matrix Composites (PMMCs) are currently being used as structural components in aerospace, automotive and industrial applications (AlAdemilua, et al., 2013; Prasad and Ramachandra, 2013; Vannan and Paul, 2014). Discontinuously reinforced metal matrix composites have received much attention because of their high specific strength and stiffness, good wear resistance and modified thermal properties, which are difficult to achieve in a monolithic metal alloy or conventional material (Wahab, et al., 2009; Naher, et al., 2003). These materials have emerged as an important class of advanced materials giving engineers the opportunity to tailor material properties to various engineering applications (Naher, et al., 2003). PMMCs combine the ductility and toughness of the metal matrix with the high strength and stiffness of the ceramic rein- 


\section{Apasi et al.}

forcement ( $\mathrm{SiC}, \mathrm{Al}_{2} \mathrm{O}_{3}$ ) to achieve better properties (Vannan and Paul, 2014). The outstanding properties of PMMCs include high strength to weight ratio, excellent mechanical properties coupled with wear resistance and thermal stability, which makes them desirable as engineering material for various structural, automotive, aerospace, sports and tribological applications (Vannan and Paul, 2014;, 2007). Small particulate (less than $1 \mu \mathrm{m}$ ) dispersion into metals induces an Orowan strengthening mechanism, which in turn improves the strength of the material (Minlin et al., 2014). Traditionally, high modulus ceramic particulates such as silicon carbide ( $\mathrm{SiC})$ and alumina $\left(\mathrm{Al}_{2} \mathrm{O}_{3}\right)$ have been used for reinforcements purposely for stiffness and strength enhancement. It is however known that, additional and tailored properties can still be achieved by carefully controlling the properties of the matrix, the reinforcement and the interface formed between them (Ademilua, et al., 2013; Prasad and Ramachandra, 2013; Dobrzanski, et al., 2010).

Particle reinforced MMCs are produced through various routes such as powder metallurgy, liquid metallurgy, squeeze casting rolling and extrusion techniques (Deuis, et al., 1997). However, liquid metallurgy technique (stir casting) is chosen as a promising route due to its versatility, low cost, and its efficiency to homogeneously distribute the reinforcement in the metal matrix for mass production (Kevin and Sijo, 2015).

Various works have been done on stir casting of aluminium alloy composites using different kinds of reinforcements such as synthetic ceramic particulates $\left(\mathrm{SiC}, \mathrm{Al}_{2} \mathrm{O}_{3}\right)$, industrial wastes (flyash, red mud), and agro-waste (rice husk, bamboo leaf ash) derivatives with outstanding results.

Prasad and Ramachandra evaluated factors affecting sliding wear behaviour of Al-flyash metal matrix composites using stir and squeeze casting techniques. It was reported that the addition of the flyash by weight percentage and the applied squeeze pressure caused the improvement in hardness and wear resistance of the composite (Prasad and Ramachandra, 2013). Similarly, an increasing trend of hardness and impact strength with increase in weight percentage of $\mathrm{SiC}$ was observed by Deepak et al (2009). They submitted that the optimum hardness and impact strength of 45.5 BHN and $36 \mathrm{~N}-\mathrm{m}$ were achieved at $25 \% \mathrm{wt}$ fraction of $\mathrm{SiC}$.

Similar results were reported with several other agro-waste (palm oil clinkers, rice husk, and coconut shell), where enhanced mechanical properties of the composites were achieved at low cost (Lancaster, et al., 2013).

A published study on the mechanical properties and corrosion behaviour of aluminium hybrid composites reinforced with silicon carbide and bamboo leaf ash (BLA) showed that the hardness, ultimate tensile strength and percentage elongation of the hybrid composite decrease with increase in BLA. However, the result of $\mathrm{Al}-10 \mathrm{wt} \%$ of $\mathrm{SiC}$ single reinforcement of the same study, presented superior mechanical properties. Moreover, in separate studies investigating the tribological properties of reinforced aluminium alloy basalt and beryl particulate composites (Vannan and Paul, 2014; Abdul and Bhaskar, 2012), both basalt and beryl particulates are reported to significantly improves the hardness and sliding wear resistance of the aluminium alloy due to the hardness of the particles and the formation of triboinduced rich basalt short fibre film on the mating surfaces. Coconut shells (agro-waste material) as aforementioned have suitable particulate reinforcement properties. These materials are readily available in Nigeria but they are considered to be of little or no economic importance. The realization of these materials through continuous research is pertinent to achieving a low cost metal matrix composite production technique with uncompromised strength for various engineering applications. Very few studies have been focused on coconut shells in metal matrix composite. In the works 
of Apasi et al., (2012) and Madakson et al., (2012), they both separately concluded that CSAp could be used in the production of light weight metal matrix composite with good thermal and wear resistance.

Daramola et al., (2015) evaluated the mechanical and corrosion properties of Al 6063 alloy/ coconut shell composites. They noticed increase in hardness, tensile strength with increase in percentage weight of coconut shell with decrease in corrosion resistance. Agunsoye et al (2014) obtained similar result that the mechanical and wear properties of recycled waste aluminium can be reinforced with coconut shell. Conversely, the effects of CSAp on mechanical properties of aluminium silicon iron alloy have not been reported to the best of authors' knowledge. Thus, the objective of this work is to improve the mechanical properties of $\mathrm{Al}-\mathrm{Si}-\mathrm{Fe}$ alloys by CSAp addition and investigate its effects on other properties of the resulting composite.

\section{MATERIALS AND METHOD}

The materials used in this work include coconut shells obtained from a coconut seller, $99.70 \%$ purity aluminium cables of $2.5 \mathrm{~mm}$ diameter from Northern Cable Company (NOCACO), Kaduna, Nigeria as the matrix, silicon Tokuyama Corporation Chemical industry) and iron powder of $50 \mu \mathrm{m}$ grain size (Xi' AnLanzhiguang Fine Material Co., Ltd China).

\section{Preparation of coconut ash particulates}

The coconut shells were first ground to form powder (Fig. 1a) and fired at a temperature of $1300{ }^{0} \mathrm{C}$ for 3 hours in a graphite crucible using an electric resistance furnace, to form the coconut shell ash powder (CSAp) as shown in Fig. 1b. The particle size analysis of the coconut shell ash was carried out in accordance with BS1377:1990 (Prasad and Ramachandra, 2013; Aigbodion, 2007; Bienia, et al., 2003). About $100 \mathrm{~g}$ of CSAp was put in a set of sieves arranged in descending order of fineness and shaken for 15 minutes in accordance with the recommended time for achieving complete classification. Particles of size $100 \mu \mathrm{m}$ of the reinforcement were used in this investigation due to its fine nature.

\section{Composite production}

The metal matrix composite was produced using the double stir-casting technique. The specimens were produced by keeping the per-

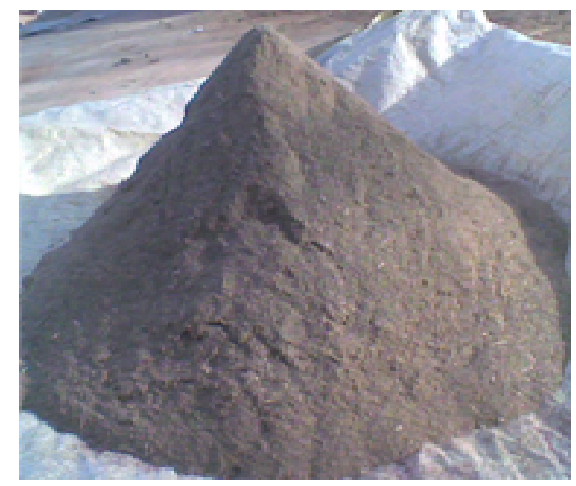

(a)

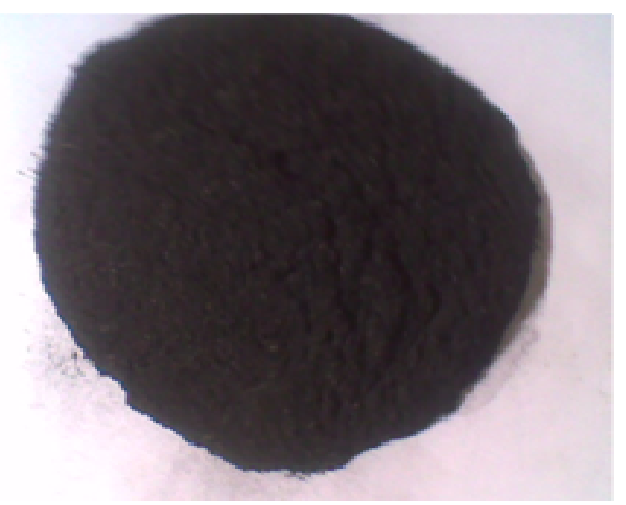

(b)

Fig.1: Photograph showing coconut (a) shell powder and (b) shell ash 
37

centage of iron powder $(2 \% \mathrm{wt})$ and silicon $(7$ $\%$ wt) in the matrix constant and varying the reinforcing material (coconut shell ash) particles in the range of $0,3,6,9,12$, and $15 \mathrm{wt} \%$. The chemical compositions of the matrix and coconut shell ash were shown in Fig. 2 and table 1 respectively. The aluminium and $7 \% \mathrm{wt}$ $\mathrm{Si}$ were then charged in a graphite crucible kept in an electric resistance furnace and heated to $750{ }^{\circ} \mathrm{C}$ till the entire alloy in the crucible completely melted. Then, $2 \mathrm{wt} \%$ iron powder was added to the melt. Degassing tablets hexachcloroethane) and $1 \mathrm{wt} \%$ magnesium were simultaneously added to reduce hydrogen entrapment and enhance wettability of the reinforcement (CSAp) and the Al-Si-Fe alloy melt respectively. A stainless steel stirrer with rotational speed of $700 \mathrm{rpm}$ (Fig. 3) was gradually lowered into the melt. The $3 \mathrm{wt} \%$ CSA particles preheated to $800{ }^{\circ} \mathrm{C}$ for one hour to promote wettability and homogenization of the composite slurry melt was added into the melt at a constant rate. The stirring of the slurry was then continued for another five minutes after the completion of CSA feeding. The mixture was poured into the steel cylindrical mould of $20 \mathrm{~mm}$ diameter by $200 \mathrm{~mm}$ long, which has also been preheated to $50^{\circ} \mathrm{C}$ for 30 minutes by a long tong for safety purpose to obtain uniform solidification in open air. The same approach was used in the production of the composites containing 6, 9, 12 and $15 \mathrm{wt} \%$ CSA particle reinforcement.

\section{Determination of the hardness value}

The hardness values of the samples were carried out in accordance with ASTM E18-79, standard, using the Rockwell hardness tester on 'B' scale with $1.56 \mathrm{~mm}$ steel ball indenter. It has a minor load of $10 \mathrm{~kg}$ and major load of $100 \mathrm{~kg}$ with hardness value of 101.2 BHN on the standard block. Calibration of the hardness tester was carried out while all the mating surfaces were thoroughly polished and cleaned with fine grain emery paper of 320 grit size before the test. The test was carried out at three different spots on the testing surfaces to avoid the possible effect of indenter resting on the harder particles and the average of all the three readings was taken. The Brinell hardness value (BHN) was obtained using the relationship below;

$B H N=\frac{F^{*}}{A_{0}}$

Where $\mathrm{F}$ is the load (kilograms) and $A_{c}$ is the

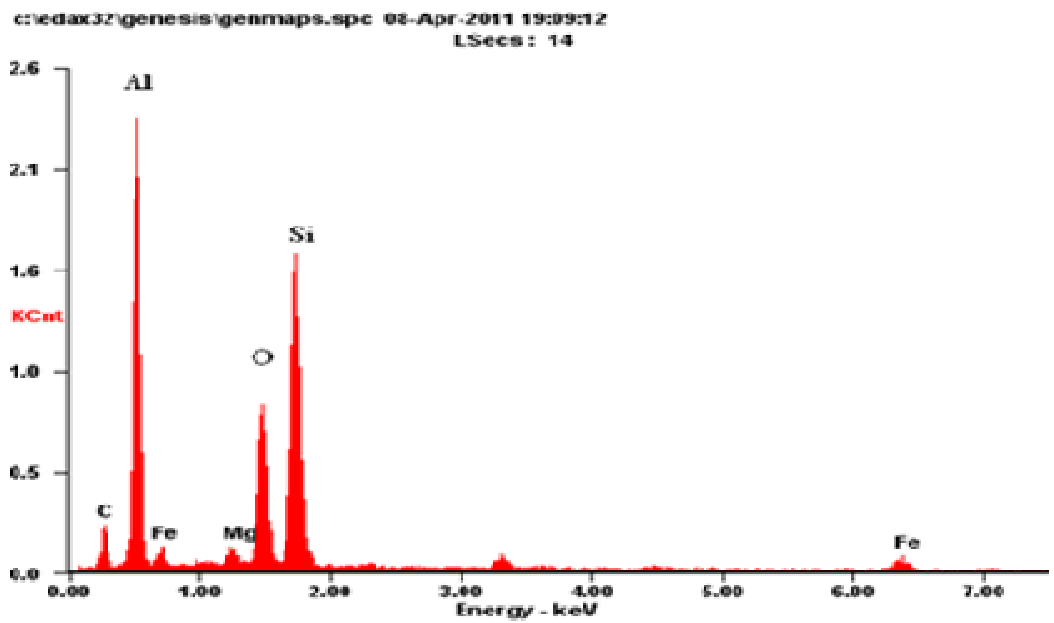

Fig 2: SEM analysis of elemental composition of aluminum alloy (matrix) 
Mechanical properties of aluminum alloy reinforced with coconut shell-ash particulate ...

Table 1: XRF analysis of elemental composition of coconut shell-ash particles

\begin{tabular}{cc}
\hline Element & \% Composition \\
\hline $\mathrm{Al}_{2} \mathrm{O}_{3}$ & 15.6 \\
$\mathrm{CaO}$ & 0.57 \\
$\mathrm{Fe}_{2} \mathrm{O}_{3}$ & 12.4 \\
$\mathrm{~K}_{2} \mathrm{O}$ & 0.52 \\
$\mathrm{MgO}$ & 16.2 \\
$\mathrm{Na} 2$ & 0.45 \\
$\mathrm{SiO}_{2} \mathrm{O}$ & 45.05 \\
$\mathrm{MnO}$ & 0.22 \\
$\mathrm{ZnO}$ & 0.3 \\
\hline
\end{tabular}

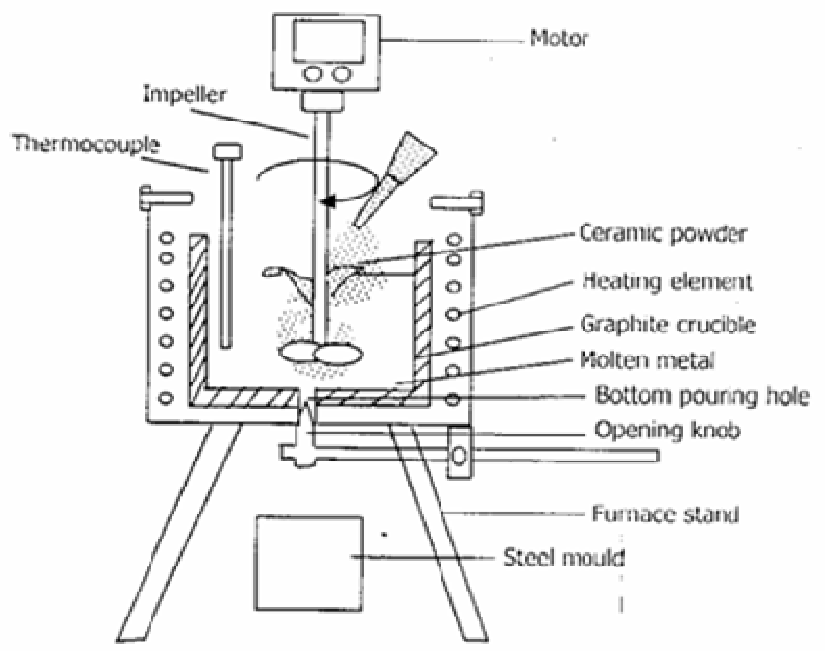

Fig. 3: Schematic diagram of stir casting technique

is the actual surface area of the indentation in square millimetres.

\section{Tensile testing}

The tensile test of the composite samples was conducted on the Tinus-Olsen tensile testing machine at a strain rate of $2 \times 10^{-3} \mathrm{~S}^{-1}$. The test pieces were machined to the standard shape and dimensions as specified by the American Societyfor Testing and Materials (ASTM -E8M). The sample was locked securely in the grips of the upper and lower jaws of the testing machine. A small load was initially applied to seat the sample in the jaws and then gradually increased until failure occurred. The value of the load and extension were recorded and used in obtaining the strength of the composite as a function of the CSAp.

\section{Microstructural examination}

Metallographic specimens were cut transversely from the unreinforced and reinforced samples of Al-Si-Fe/CSAp particulate composites (Fig. 4). The sectioned specimens were then mounted on Bakelite and mechanically ground progressively on grades of $\mathrm{SiC}$ impregnated emery paper of 80 
-600 grits sizes using water as the coolant. The ground specimens were then polished using 1$\mu \mathrm{m}$ alumina polishing powder suspended in distilled water. The final polishing was done using $0.5-\mu \mathrm{m}$ alumina polishing powder suspended in

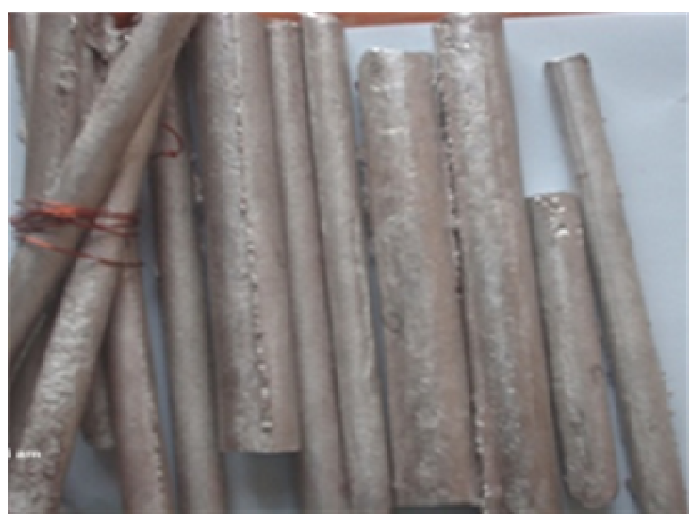

Fig. 4: Photograph of samples of the Al-Si-Fe/ CSAP composite produced

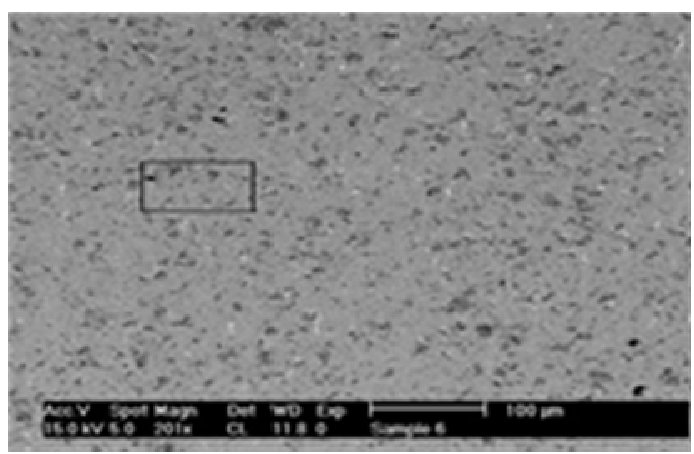

$3 \%$ wtCSAp

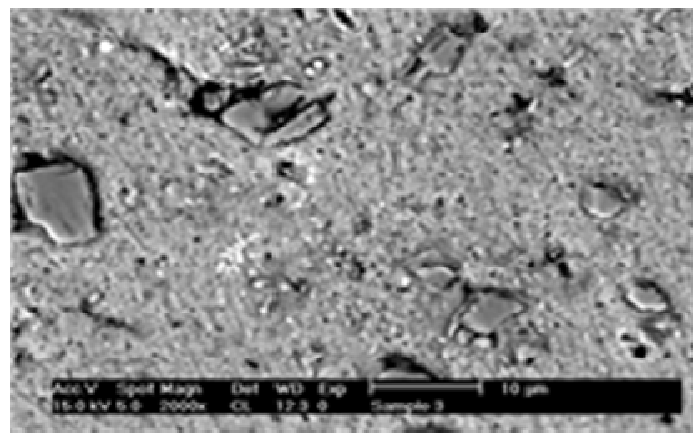

$6 \%$ wtCSAp distilled water. The etching of the polished specimen was done using Keller's reagent. The structure obtained for various additions of CSAp were observed using scanning electronmicroscope (SEM) with inbuilt camera and presented in Fig. 5.

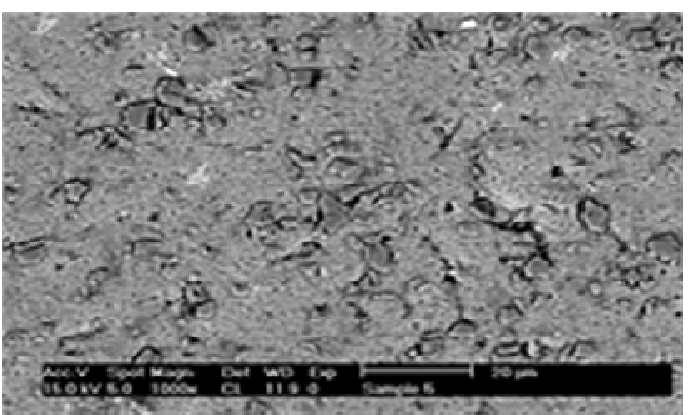

9\% wtCSAp

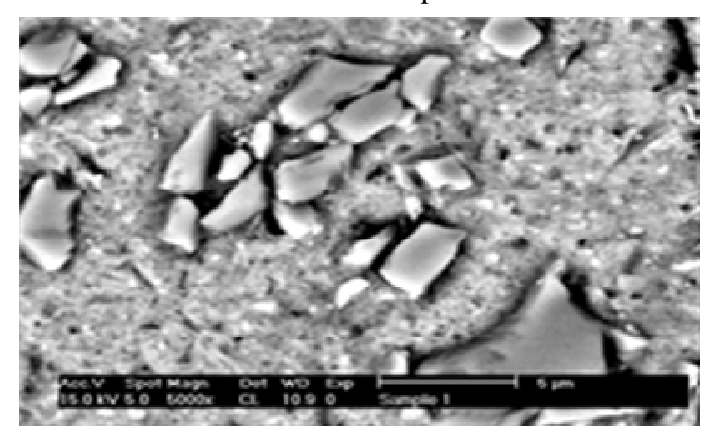

$12 \%$ wtCSAp

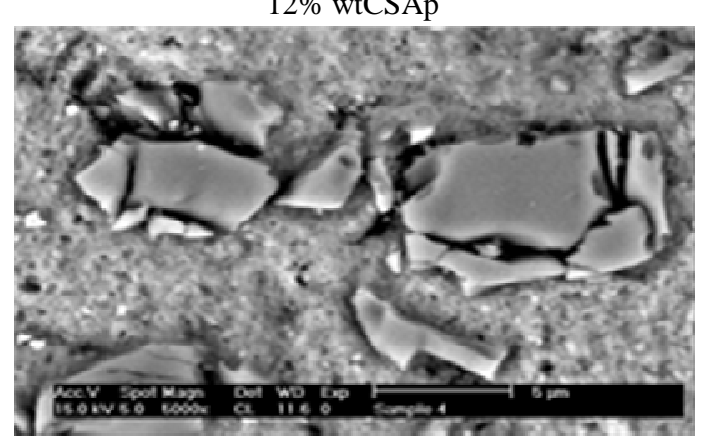

$15 \%$ wtCSAp

Fig. 5: Microstructure analysis of Al-Si-Fe/ CSAp Composites at varying CSAp weight percentage

Journal of Science and Technology @ C KNUST December 2016 
RESULTS AND DISCUSSION

Evaluation of the hardness behaviour

Hardness of the developed composites increased with increase in CSAp additions. It is noteworthy that the hardness value of coconut shell ash according to Apasi et al., (2012) is $95.05 \mathrm{HB}$ and the presence of the hard ceramic phase in the ductile matrix has resulted in the increase in hardness of the composite (Fig. 6). The hardness values increased from $63.50 \mathrm{HRB}$ at $0 \mathrm{wt} \%$ to $78.60 \mathrm{HRB}$ at $15 \mathrm{wt} \%$ coconut shell ash particles. These increments are attributed to the increase in the weight percentage of the hard and brittle phase of CSAp in the aluminium alloy matrix. This hardness of the coconut shell ash particles is obtained from the $\mathrm{SiC}, \mathrm{Al}_{2} \mathrm{O}_{3}, \mathrm{Fe}_{2} \mathrm{O}_{3}$ and $\mathrm{SiO}_{2}$ in the chemical makeup of the particles as revealed by the CSAp XRF analysis presented in Table 1. Additionally, the presence of CSAp in the alloy increase the dislocation density at the particlematrix interfaces as a result of differences in coefficient of thermal expansion (CTE) between the hard and brittle reinforced particles and soft and ductile metal matrix resulting in elastic and plastic incompatibility between the

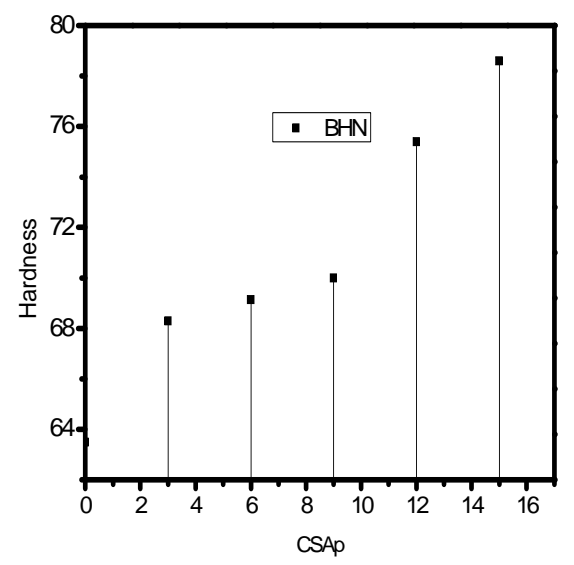

Fig. 6: Variation of hardness with \%wt of CSAp matrix and the reinforcement (Mahmoud, 2008).

Tensile properties of the composite

The result of ultimate tensile strength (UTS) and $0.2 \%$ offset yield stress (YS) of the composite at various volume fractions of CSAps is as shown in Fig. 7. The result indicates a higher value of both YS and UTS for all volume fractions of CSAp in the composite compared to aluminium alloy matrix. Both the yield and tensile strength follow the same trend and increases with increase in volume fraction of CSAp in the matrix. The maximum value of both tensile and yield strength was obtained at $9 \mathrm{wt} \%$ volume fraction of CSAp addition after which further addition resulted in gradual decrease in both the tensile and yield strengths. This increase behaviour in the tensile properties of the composites may be attributed to good particle-matrix interfacial bonding, wettability, the fine reinforcement particle size and the strengthening effect of the coconut shell ash particles in the aluminium alloy matrix. However the behaviour of the composite with CSAp volume fraction beyond $9 \mathrm{wt} \%$ weight fraction

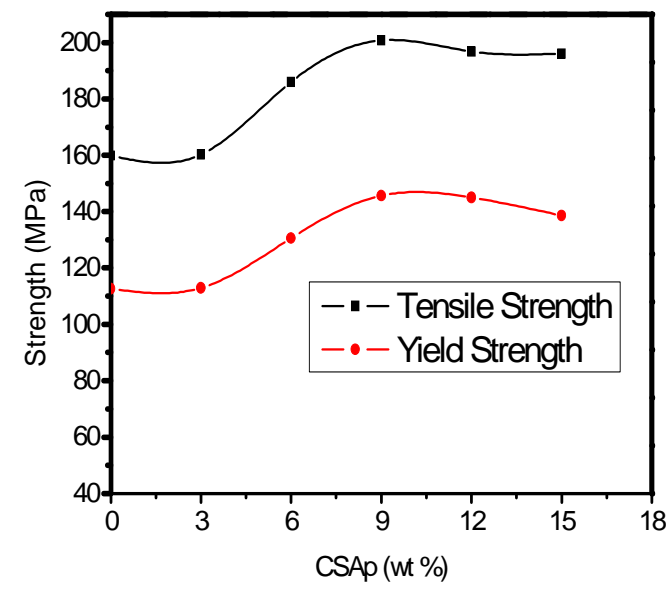

Fig. 7: Variation of strength with wt\% coconut shell ash particle 


\section{Apasi et al.}

is presumed to have been as a result of mismatch along the grain boundaries of matrixreinforcement composition. Consequently this resulted in weakening the load carrying capacity of the composite above 9 wt \% volume fraction to reduce the strength of the composite. This result is in agreement with the work of other researchers (Aigbondon and Hassan, 2013).

Macrostructural and microstructural analysis Macrostructural observation of the specimens at 50x revealed a significant uniform distribution of coconut shell ash particles (CSAp) with micro traces of some particles segregation. This is presumed to be as a result of the imbalance in density of both the matrix and the reinforcement during solidification. Notably, the result of SEM for microstructural examination of the specimens shown in Fig. 5, reveals a fairly uniform distribution of CSAp in the matrix in all \%wt addition of the reinforcements. The uniform distribution of CSAp in the matrix, can be attributed to a number of factors which includes, effective stirring of the slurry, degassing tablet used and good wettability that resulted in improved interfacial bonding between the matrix and the coconut shell ash particles (Agunsoye et al., 2014). However, micro traces of segregation/agglomeration of the reinforcement particles rarely seen at lower magnification were clearly observed at higher magnification. The maximum clustering of CSAp in the matrix was observed at $15 \%$ weight as shown in Fig. 5. This was because addition of CSAp in the matrix beyond $15 \mathrm{wt} \%$ made the composites slurry too thick with reduced fluidity and homogeneity of the molten composites. Micrographs of the microstructures of composite specimens at various fraction of CSAp are shown in Fig. 5.

\section{CONCLUSIONS}

In this work, Al-Si-Fe/CSAp composite has been successfully developed using double stir casting technique. Microstructure examination and mechanical properties (hardness, tensile and yield strength) evaluation on the developed composite samples were carried out. The fol- lowing specific conclusions can be drawn so far with the result and discussion above.

1. The hardness values of the developed composites increased with increasing percentage weight of coconut shell ash additions due to its hard ceramic phase in the matrix.

2. The addition of CSAp to Al-Si-Fe alloy matrix increased the tensile and the yield strength of the composite developed.

3. For optimum strength application, $9 \mathrm{wt} \%$ CSAp is recommended while in the case of hardness and wear resistance application, $15 \mathrm{wt} \% \mathrm{Al}-\mathrm{Si}-\mathrm{Fe} / \mathrm{CSAp}$ is recommended.

4. The economic value of waste coconut shell can be increased through the conversion of waste to wealth.

\section{REFERENCES}

Abdul, S., and Bhaskar H. B. (2012). Tribological properties of Aluminium2024 AlloyBeryl Particulate MMC's", Borfring. International Journal of Industrial Engineering and Management Science, 2(4): 143-147.

Ademilua, B. O., Alaneme, K. K. and Bodurin, M. O. (2013). "Mechanical properties and corrosion behaviour of aluminium hybrid composites reinforced with silicon carbide and bamboo leaf ash". Tribology in Industry, 35(1): 25-35.

Agunsoye, J. O., Talabi, S. I., Bello, S. A. and Awe, I. O. (2014). "The effects of Cocos Nucifera (Coconut Shell) on the mechanical and tribological properties of recycled waste aluminium can composites". Tribology in Industry. 36(2): 155-162.

Aigbodion, V. S. and Hassan, S. B. (2015). "Effect of eggshell on the microstructures and properties of Al-Cu-Mg/eggshell particulate composites". Journal of King Saud University-Engineering Sciences, 26: 49 -56 
Mechanical properties of aluminum alloy reinforced with coconut shell-ash particulate ... 42

Aigbodion, V. S. (2007). "Particulatestrengthened of Al-Si alloy/alumino silicate composite", Materials Science and Engineering A.460-461:574 - 578 .

Apasi, A., Madakson, P. B. and Yawas, D. S. (2012). "Characterization of coconut shell ash for potential utilization in metal matrix composites for automotive applications". International Journal of Engineering Science and Technology, 4(3): 1190-1198.

Bienias, J., Walczak, M.,Surowska, B. andSobczak, J. (2003). "Microstructure and Corrosion behaviour of aluminium flyash composites". Journal of Optoelectronics and Advanced Material, 5(2): 493-502.

Daramola, O.O., Adediran A. A. and Fadumiye, A. T. (2015). "Evaluation of the Mechanical Properties and Corrosion Behaviour of Coconut shell ash reinforced Aluminium (6063) alloy Composites". Leonardo Electronic Journal of Practices and Technologies, 27: 107-119.

Deepak, D., Lakhvir, S., Manoj, S. and Vikas, C. (2009). "Development of aluminium based silicon carbide particulate metal matrix composite". Journal of Mineral and Materials Characterization and Engineering, 8 (6):455-467.

Deuis, R. L.,Subramanian, C. and Yellup, J. M. (1997). "Dry sliding wear of aluminium composites-a review". Journal of Composites Science and Technology, 57:415-435.

Dobrzanski, L. A., Adamiak, M., and Kremzer, M. (2010). "The influence of reinforcement shapes on wear behaviour of aluminium matrix composite materials". Journal of Achievements in Materials and Manufacturing Engineering, 42(1-2): 26-32.

Kevin, K. P. and Sijo, M. T. (2015). "Effect of stirrer parameter of stir casting on mechanical properties of aluminium silicon carbide composite". International Journal of Modern Engineering Research, 5(8):43-49.

Lancaster, L., Lung, M. H. and Sujan, D. (2013). "Utilization of agro-industrial waste in metal matrix composites: towards sustainability". International Journal of Environmental, Chemical, Ecological, Geological and Geophysical Engineering, 7(1): 25 - 33.

Madakson, P. B., Aigbondon, V. S., Apasi, and Yawas, D. S. (2012). "Wear behaviour of Al$\mathrm{Si}-\mathrm{Fe}$ alloy/coconut shell ash particulate composites", Tribology in industry, 34(1): 36 -43 .

Mahmoud, T. S. (2008. "Tribological behaviour of A390/Grp metal matrix composites fabricated using a combination of Rheocasting and squeeze casting techniques”. Journal of Mechanical Engineering Science, 222 (2): 257-265.

Minlin Z., Dafa J. and Hongjun Z. (2014). "Fabrication of Nano-particulate reinforced metal matrix composites by Lasser cladding". Journal of Laser Applications, 26(2):1 $-11$

Naher, S., Brabazon, D., and Looney, L. (2003). "Simulation of the stir casting process". Journal of Material Processing Technology, 143-144: 567-571.

Prasad K. N. P. and Ramachandra, M. (2013). "Evaluation of factors affecting sliding wear behaviour of Al-flyash metal matrix composites by using design of experiments". International Journal of Modern Engineering Research, 3(5):2591-2599.

Vannan, S. E. and Paul, V. S. (2014). "Tribological behaviour of basalt fiber reinforced aluminium alloy journal bearings". International Journal of Advanced Engineering Applications, 7(2): 82-90.

Wahab M. N., Daud, A. R., and Ghazali, M. J. 


\section{Apasi et al.}

(2009). "Preparation and characterization of stir-cast aluminium nitride reinforced alu-

tional Journal of Mechanical and Materials minium metal matrix composites". Interna-

Engineering (IJMME), 4 (2):115-117. 